\title{
Understanding English Language Learners: Incorporating Our Own Cultural Narratives in TESOL Education
}

\author{
Burcu Ates \\ Sam Houston State University, bxa013@shsu.edu \\ Soonhyang Kim \\ Pace University, skim2@pace.edu \\ Yurimi Grigsby \\ Concordia University Chicago, yurimi.grigsby@cuchicago.edu
}

Follow this and additional works at: https://digitalscholarship.unlv.edu/jpme

\author{
Repository Citation \\ Ates, Burcu; Kim, Soonhyang; and Grigsby, Yurimi (2015) "Understanding English Language Learners: \\ Incorporating Our Own Cultural Narratives in TESOL Education," Journal of Praxis in Multicultural \\ Education: Vol. 9: No. 1, Article 3. \\ DOI: $10.9741 / 2161-2978.1074$ \\ Available at: https://digitalscholarship.unlv.edu/jpme/vol9/iss1/3
}

This Article is protected by copyright and/or related rights. It has been brought to you by Digital Scholarship@UNLV with permission from the rights-holder(s). You are free to use this Article in any way that is permitted by the copyright and related rights legislation that applies to your use. For other uses you need to obtain permission from the rights-holder(s) directly, unless additional rights are indicated by a Creative Commons license in the record and/ or on the work itself.

This Article has been accepted for inclusion in Journal of Praxis in Multicultural Education by an authorized administrator of Digital Scholarship@UNLV. For more information, please contact digitalscholarship@unlv.edu. 


\section{Understanding English Language Learners: Incorporating Our Own Cultural Narratives in TESOL Education}

\section{Cover Page Footnote}

This research was supported in part by grants from Grants for the Thinkfinity Initiative: Innovative Teaching, Technology and Research by Pace University \& Verizon. 


\section{Understanding English Language Learners: Incorporating Our Own Cultural Narratives in TESOL Education}

\section{Introduction and Background}

There is no field other than education that is more aware of the diversity in the U.S. (Linn, 2010). According to the U.S. Census Bureau (2010), by the year $2023,50 \%$ of the student population under age 18 will consist of minority (racially and ethnically other than White) students. Children of immigrants are the fastest growing youth population and are transforming the current American school system by making it more culturally and linguistically diverse than ever before. It is projected that in 2043, the U.S. will become a majority-minority nation for the first time in its history. Although the non-Hispanic White population will still remain the largest single group, no group will make up a majority (U.S. Census, 2010).

Racial, ethnic, and linguistic student diversity in classrooms is increasingly becoming the norm rather than the exception, yet our teaching force is dominantly female, consisting of $76 \%$ of teachers, and $83 \%$ being White (Feistritzer, 2011). Therefore, a significant gap between teachers and the diverse student population exists (Delano-Oriaran \& Meidl, 2013; Gay, 2010; Nieto, 2010; Spradlin, 2011). Teachers will need to develop the skills and strategies for connecting with students whose backgrounds may be vastly different from their own (Kim, Grigsby, \& Micek, 2013; Kim, Micek, \& Grigsby, 2013).

Making the teaching practice and learning experience meaningful for preand in-service teachers of English language learners (ELLs) is a complex task. With the increasing number of culturally and linguistically diverse students, de Jong and Harper (2005) state that the "just good teaching" (p. 102) approach, "activating prior knowledge, using cooperative learning, process writing, and graphic organizers or hands-on activities" (p. 102), is simply not enough.

The purpose of this paper, therefore, is to suggest how teacher educators' own cultural narratives ( $\mathrm{CNs}$ ) can be incorporated into teacher education for educating pre- and in-service teachers to work with culturally and linguistically diverse (CLD) students. Applying CNs mean sharing personal and cultural narratives with the teacher candidates during periods of instruction (Conle, 2000). This paper is designed to present helpful ways all educators can utilize cultural narratives in their teaching. To do so, we describe Burcu's, one of the authors, a non-native English-speaking (NNES) Turkish teacher educator's integration of her own CNs in a teacher training course, after a brief review of current classroom contexts and use of $\mathrm{CNs}$ in teacher education. Additionally, we present ways cultural narratives can be tailored to others' pedagogy through the lessons learned by Burcu who successfully merged her authentic background into her own 
instruction. This paper epitomizes Palmer's (2012) words, "We teach who we are" but we learned through our reflective process that we also teach how we are. In other words, we cannot help but bring our authentic selves with us into the classroom.

\section{Cultural Narrative-Incorporated Instruction in TESOL Education}

One way to bring our authentic selves in the classroom is through incorporating CNs as an instructional tool for training Teachers of English to Speakers of Other Languages (TESOL). Two senior university lecturers, Hellstén and Goldstein-Kyaga (2011), believe:

Story telling in the classroom is a great motivator for learning, as the sequential order of tellings raise both curiosity and interest in discovery of what lies ahead. Unfortunately, only a modest amount of university teaching is provided in this entertaining but effective way (p. 170). Carter (1993) also discusses in teacher education how "stories capture, more than scores of mathematical formulae ever can, the richness and indeterminacy of our experiences...the complexity of our understandings" (p. 5). Stories are products of the human experience. In making stories and reading the stories of others, we can use them to make sense of the world (Bruner, 2003).

Hellstén and Goldstein-Kyaga (2011) documented their own intercultural narratives and shared how they use the narratives as instructional tools in their own classroom. They noted that storytelling in the university classroom is an influential motivator for learning because the sequential order of stories creates curiosity and interest for the students, who are waiting for the next story the instructor is going to share and connect to the topic being studied.

Through our review, we identified a gap in the literature in terms of lack of studies where a teacher educator, specifically a TESOL educator, documented the use of his or her own cultural narrative in the classroom as an instructional tool when teaching ESL-related courses. Our recent research article in 2013 (Kim, Ates, Lee, \& Grigsby, 2013; Kim, Ates, Grigsby, \& Lee, 2013) introduced four $\mathrm{CNs}$ of Burcu and reported in what ways her narratives can inform pre- and inservice teachers who will be/are teaching ELLs using the "reflective team approach" (Jones, 2003) by four TESOL educators. We concluded that integrating the authentic firsthand stories of a teacher educator who was once an ELL herself has great potential for educating teacher candidates on issues related to language, culture, identity, and diversity. This is the only study, to the best of our knowledge, which incorporated teacher educators' own CNs in TESOL education.

To address this gap and having been inspired by our initial study, we decided to further explore the power of cultural narratives in teacher education by documenting CNs' actual use as an instructional strategy to positively and 
authentically impact pre- and in-service teachers' awareness raising and developing knowledge to better respond to the academic and linguistic needs of ELLs. This paper is significant that this is an attempt to show the potential usefulness of narrative-incorporated instruction and contributes to the literature in the area of teacher education, specifically TESOL education. We propose the use of CNs as an effective instructional tool to train pre- and in-service teachers and demonstrate the applicability of CNs for other TESOL educators by documenting a sample of $\mathrm{CN}$-incorporated instruction in a TESOL course taught by Burcu.

\section{Institutional Contexts}

The university where Burcu incorporated her cultural narratives, is known as one of the oldest PreK-12 teacher training institution in Texas. The teacher candidates are predominantly White, female, and middle class. Being one of the largest ELL student populations in public schools in the U.S. (U.S. Department of Education, National Center for Educational Statistics, 2009-2010), preparing teacher candidates in Texas to meet the needs of ELLs is extremely crucial. All of the EC- 6 teacher candidates are strongly encouraged to be additionally certified in ESL given the needs of many ELLs in the classrooms. Therefore, almost all teacher candidates take the state's ESL-certification exam as an add-oncertification.

Three mandatory ESL and multicultural education courses for EC-6 teacher candidates are offered through Burcu's program area, ESL and bilingual education: (1) Multicultural Influences on Learning, (2) Second Language Acquisition, and (3) Literacy Strategies for English Language Learners. The goal of these three courses for EC- 6 teacher candidates is to make them aware of issues related to diversity in society and schools and help them understand the second language learning process and prepare them to successfully meet the needs of ELLs with appropriate instructional methods and strategies.

\section{Course Description of a CN-Incorporated Course}

Burcu's CN was incorporated in Literacy Strategies for English Language Learners course. This course is similar to an ESL methodology course, however, mainly focusing on teaching reading and writing strategies for ELLs. The course is designed to have teacher candidates gain first-hand experience working with linguistically and culturally diverse students in Texas schools. To do so, linguistic and cultural principles, lesson planning, practical methods, curricula and materials for teaching English to speakers of other languages in EC-6 grade classrooms are covered in this class. This course is offered only face to face and is the last required ESL-related course offered to teacher candidates who specialize in 
elementary school teaching. After this course, the undergraduate teacher candidates are eligible to take their state ESL-certification exam.

The course met for three hours over a fifteen-week semester in Fall 2012. Burcu taught two sections of this course in Fall 2012. In one section, there were 31 students, all of them were females except one male student. In the second section, there were 27 students and out of all students only 2 were males. About $70 \%$ students were predominantly White, the rest were Hispanic and African American students.

Two textbooks were used throughout the semester, one on differentiated literacies and the other on content strategies for ELLs. In this course, the students were required to complete several assignments such as assessing an ELL's academic and social oral proficiency using a student oral language observation rating scale, then creating a Sheltered Instruction Observation Protocol (SIOP) lesson plan based on the assessment to improve his/her speaking skills for ELLs (Echevarria, Vogt, \& Short, 2004). Teacher candidates were also involved in assessing an ELL's writing sample using a writing rubric created for the purpose of creating English language proficiency standards and assessments. Another major assignment was a strategy workshop, where teacher candidates, in groups, teach two or three ELL teaching strategies to classmates in mini-lesson/workshop format.

\section{A Sample of CN-Incorporated Instruction: Accent}

Burcu incorporates her $\mathrm{CNs}$ in her course as much as possible as long as her CNs align with the course content. Here is a sample of a $\mathrm{CN}$ Burcu incorporated in Week 8 , when the course addressed various listening and speaking teaching methods and strategies. Burcu integrated the sociolinguistic and sociocultural point of view into the class before delving into these two language skills. This means the class was designed to not only focus on teaching strategies but also to help teacher candidates become aware of how speakers' oral proficiency can either grant access or perpetuate discrimination or unequal power relationship in society (Lippi-Green, 2012).

The topic of listening and speaking was introduced in Week 8. Students were required to read some reading materials to build up background knowledge in speaking and listening and learn specific classroom strategies from the course textbook before class. At the beginning of the listening and speaking class, preservice teachers' attention was drawn to how speaking seems to be valued more than listening in society by people first asking, "Do you speak [English]?" initially focusing on speaking. Some pop-culture videos were also introduced to get their attention and discuss elements about speaking, specifically about accents and how these are portrayed in the media. One of the clips was about Sophia 
Vergaras' character, Gloria, in the television show Modern Family (http://www.youtube.com/watch?v=bKwOoRd5tHk), in which discussion centered on how her foreign accent has become a tool for laughing. It is the same with Kunal Nayyar's character Raj in The Big Bang Theory (http://www.youtube.com/watch?v=dOgdhqtGu98). Raj's Indian accent again becomes a tool for his peers in the show to make fun of him or for the audience to laugh at.

Then, Burcu incorporated her own $\mathrm{CN}$ by sharing stories of how she was perceived in the U.S. about ten years ago, when she used to have a thicker accent than now. Back then, she was an international doctoral student from Turkey and had been in the U.S. for 3 years. Below is the full written story, which was shared orally in class.

\section{Burcu's CN: My Thick Turkish Accent}

About ten years ago, when I used to have a thicker accent than now, I recall asking for directions while driving (this was before GPS technology) in southeast Texas. People would often automatically increase their voices as if I were hard of hearing and could not hear them as they described the route to me. I would always want to say "I can hear you fine; you don't need to speak S-L-O-W and shout at me." Of course, I never said anything like this because I did not want to be rude, and I was appreciative of the kind act of simply taking the time to explain the location of my destination. Yet similar experiences seemed to happen repeatedly to me in different contexts, either when shopping or running other errands, while at school, you name it. I would go shopping and feel as if I were being treated as an incapable customer when all I asked was a simple question. It is as if I can feel the mental halt happening in the brain of the person in front of me as they realize they are speaking to someone with an accent. Sometimes I wonder if in their eyes they are saying, "Oh no...this will take time and effort." On a different note, I always wonder if the people who judged me to be an incompetent individual ever reflected on how they sounded to others, and if they are aware of how all marginalized accents (i.e., those that tend to be non-British) carry with them perceptions of the people who speak them in the listener. Knowing what I have been through as an adult who is in the ESL profession, I cannot help but feel sadness toward our ELL students and the hardships they may be going through in schools simply due to their accents.

(Source: Kim, Ates, Lee, \& Grigsby, pp. 188-189, 2013) 
After sharing the $\mathrm{CN}$, Burcu asked her students what their reaction was to her story. She asked them if they witnessed any event themselves between a Native English Speaker (NES) and a Non-native English Speaker (NNES) where the NES was having trouble understanding the NNES's accent. She then asked them probing and compelling questions, "How was the dynamics of their interaction? Did the NNES look empowered or disempowered?" The class elaborated on these questions through discussion.

Next, students watched the classic documentary American Tongues (1988), an award-winning, sociolinguistic documentary that examined American English dialects, accents, and perceptions. Her own accent-related $\mathrm{CN}$ and the discussion on accents in American Tongues complemented each other well because she first discussed her own story as a NNES, then listened to other NESs' stories. The documentary was intended to have the students realize as NES they were not immune to marginalization. In class, they also referred back to The New Americans (2004) documentary they initially watched at the beginning of the semester. This documentary is about the lives of immigrants and refugees before and after they come to the U.S. They remembered how one of the Nigerian sisters cried on the school bus after one of her peers made fun of her accent. It was a powerful section in the documentary to reflect on because it vividly portrayed how hurt this refugee female student who spoke English with an African accent felt after her encounter with a peer.

It is during this time that Burcu asked students to share their own stories, if any, of being discriminated by other native speakers due to their accent. She asked this question because she wanted them to realize, if they shared any stories, that accent was not an issue exclusive to nonnative speakers of English. Sharing their stories with their peers makes it more powerful and real to them as a valid experience (Barhuizen \& Hacker, 2009; Bruner, 2003). Next, they discussed ELLs with accents and how NNESs may face double marginalization, first, because they have an accent, and second, because it is a foreign accent. Through this discussion, students made natural connections to intelligibility and comprehensibility issues (Kennedy \& Trofimovich, 2008) among NNESs that helped them to realize that someone's accent does not matter as long as one can understand them.

Beyond the face-to-face meeting, the discussion of this topic carried over to the online discussion forums every other week that students made on different topics related to class. In the following online discussion on Blackboard, Burcu posed the question below for further discussion to help pre-service teachers apply what they learned from the accent topic into their own current or future teaching: 
Now, think about your own 'future' classroom:

For example, you have a native English speaking student with a different American accent and his/her peers/classmates are making fun of the way he/she speaks, or you have a non-native English speaking (ESL) student with a different foreign accent and the same incident is happening. How would you deal with the situation as the classroom teacher?

Please explain.

(Source: Blackboard online discussion, Week 8, fall 2012, Literacy Strategies for English Language Learners course)

This online discussion, which asks EC-6 grade classroom preservice teachers to explain how they would deal with a classroom situation where one student is being made fun of due to accent resulted in the preservice teachers developing a greater stance of advocacy, united in their decision of educating and having an open conversation with their NES students as well as other NNES students about the appreciation of various accents.

\section{Some Evidence of the CN-Incorporated Instruction}

The teacher candidates who received the $\mathrm{CN}$-incorporated instruction seemed to be receptive to these stories and provided positive feedback, showcasing the effectiveness of connecting with the personal experiences that matched those of their instructor. Some evidences, even if not formally assessed, support its effectiveness through the end-of-semester course evaluations and the student comments within them. One such element was pre-service teachers felt that what made the CNs meaningful to them was the authenticity housed within the narratives. In other words, their comments expressed an appreciation and insight into the experiences of an ELL that was made deeper not through a textbook or unfamiliar article from an unknown entity, but through their instructor, the person standing before them. Addressing accents also gives an opportunity for many teacher candidates to reflect on a topic they may not have thought about before. For example, after first hearing the story of their own instructor and then discussing their own perspectives on accents in class, one student in an online discussion shared:

Half of my family live in California and when I go visit them they all make fun of me when I say y'all! They always say that I'm so "country" and they repeat y'all so many times as if it is a foreign word.

Providing the space for stories creates room for rumination and invites reflection by the candidate on further directions for a topic. One student stated: 
We need to teach our students that everyone is and sounds different and that is what makes this world an interesting place to live in. If a student has an unfamiliar accent or is from another place that students have never heard of, the teacher should allow time for the student to teach the class about it and even design lessons around all the students different cultures. Another student stated her further action plan in her own classroom as: "In my future classroom I would like to have a unit about what makes us unique, including accents."

Along with the teacher candidates' positive feedback, Burcu also noticed a positive shift in student perceptions towards her as a non-native speaker of English since she began incorporating her own personal and cultural narratives in her instruction. Before using narratives as an instructional tool, her foreignness was frequently identified as a problem or something negative: "She is Turkish so it is difficult to understand her," "She is foreign."(end of semester student evaluation comments) However, Burcu believes once she incorporates her own stories into the instruction, her students do not seem to evaluate her foreign identity as a weaknesses; at least they never mention it in her evaluations anymore. She feels as though her students now understand her story and where she comes from and that learning a new language is never an easy task. This can be an evidence of the $\mathrm{CN}$-incorporated instruction.

It is hard to formally claim, further formal observation and analysis are needed, that $\mathrm{CN}$-incorporated instruction are fully effective. However, our literature review and this specific $\mathrm{CN}$ example suggests that $\mathrm{CN}$-incorporated instruction produced an authentic and meaningful context in which students became more willing to see the positive aspects of having a diverse teacher who had a different background from their own - much like diverse students they are going to have in their own future classroom. An added benefit from this method is that it may be an empowering experience for all NNES teacher educators who may feel disempowered in the U.S. classroom at times (Curtis \& Romney, 2006). Sharing our stories can be a quite powerful bridge which connects NNES educators to NES students in the classrooms. Burcu's use of CNs as an instructional approach humanize a deep and complex subject matter that can so often become impersonal, decontextualized, and abstract. It is in this way that education becomes a very poignant experience.

\section{Recommendations for Effective CN-Incorporated Instruction to Broadening the Lens}

Cultural narratives highlight differences that may exist from family to family, yet also connect us through our similarities as human beings. This narrative also reaffirms the importance of sharing powerful documentaries in 
courses such as second language acquisition, sociolinguistics, or multicultural education through which pre- and in-service teachers can watch and hear the stories of language learners' journeys. Whether or not students agree with the author of the story, pre-and in-service teachers should be able to think critically, understand, and reflect on stories with different perspectives.

We believe sharing narratives of self or others is one of the ways to help teacher candidates "to be equipped with ways to better understand others and to become more aware of their own identities in an effort to better serve the needs of all students in diverse settings" (He \& Cooper, 2011, p. 111). We can use our personal and professional stories to connect with students and provide a safe, comfortable classroom for student learning. Relationship-building is crucial. As Burcu shared, she used her narratives to share the journeys of ELLs and wanted pre-service teachers to empathize with language learners' struggles. Through the sharing of narratives, students may come to the realization that teachers are not only transmitters of knowledge but human beings with a story and background. As Connelly and Clandinin (2000) mention, they "do not see teacher knowledge as something fixed and static to be replaced by something else, but as something lifelike, something storied, something that flows forward in ever changing shapes" (p. 318). An important point though is that the stories shared by the instructor needs to be purposeful, not meaningless time-fillers.

Through this study, however, we found other ways cultural narratives could either be introduced or experienced in the classroom while both teacher and student familiarize themselves with working with narratives. One such method is finding and utilizing the cultural and personal narratives of our own and others'. Even a short introduction of who we are in Day 1 can be an effective step that allows our students to understand their instructor. It is important for pre- and inservice teachers to make an effort to talk about themselves but also to hear about their ELLs in the classroom. Connecting with each other is key when teaching a diverse student population and in teaching diversity to future teachers with limited experience with diversity (Spradlin, 2011).

Here are more recommendations based on the literature review and the aforementioned sample of a $\mathrm{CN}$-incorporated instruction to train our pre-service teachers to work with ELLs.

\section{Include an introductory exercise into instruction to help teacher candidates learn how to utilize their own stories in their own classroom}

Having students create their own stories is a powerful means of validating the knowledge and experiences they bring with them into the classroom. As an introduction to this method, a simple activity students can do is to take a few minutes to free-write, jotting down a brief memory they have associated with a 
general topic (e.g., their grandmother, or Halloween). In small groups or with their "shoulder partners," students can share this memory orally. The next task would be to relate this story to a topic or theme that they might address in their curriculum. This activity could end with this connection or could be expanded to give them an opportunity to prepare a mini-teaching lesson, using their single narrative example as an introduction to a lesson plan or ice-breaker activity.

\section{Using stories from readily available documentaries}

This is important because documentaries such as American Tongues and The New Americans can help pre- and in-service teachers see the scope of language learning and that it does not consist of only grammar and rules. Cultural narratives can be explored through documentaries such as The Color of Fear (1994) (which investigates race/ethnicity issues) and Dying to Live: a Migrant's Journey (2005) (which investigates citizenship and issues of the undocumented). They can also be examined through inspirational talks such as The Danger of a Single Story (2009) by Chimamanda Adichie (which discusses the negative impacts of knowing only one side of the story).

\section{Utilize technology to enhance $\mathrm{CN}$-incorporated approach}

Another method is by utilizing technology to increase the ways students may create and deliver their narratives. Instructors can utilize technology for creating and sharing CNs to facilitate their incorporation into instruction by writing their stories (i.e., in a vignette format) and videorecording their stories for classroom use or posting them online. Students with whom the video is shared can also read the written vignette to later reflect on the narratives and critically examine how the narrative applies to the classroom content or their knowledge about ELLs.

Students can also videorecord their story or the stories of others through student-centered projects like digital storytelling. In this student-centered method, individuals get to tell their story their way by choosing the topics and visual images that help them to tell their story. In addition, documentaries can easily be streamed by the Instructional Technology (IT) departments at the institutions, or clips of many documentaries such as American Tongues can be found on YouTube, like Burcu did. Critical questions with regards to documentaries and course materials can be posted online for online discussions. 


\section{Conclusion}

We, three authors as a reflective team, introduced how Burcu implemented $\mathrm{CN}$ - incorporated instruction as a teaching strategy to train teacher candidates to work with ELLs in their own classroom. After the review of cultural narrative and its use within TESOL instruction, as we documented earlier, CNincorporated instruction can be an effective means of delivering content that is intensive, sensitive, and complex. This method also preserves the safety and security of students while they work through the process of understanding and valuing the knowledge and experiences of the diverse learner. Undoubtedly, there will be challenges associated with incorporating CNs into instruction. For instance, narratives are often personal and uniquely individual, and they do not provide solid conclusions or easy solutions to problems or conflicts that the narratives might bring to light and the discussions that arise out of them.

As Atkinson (2010) stated, "the difficulty in examining narrative inquiry is its "attention to personal experience narrated and examined as knowledge" ( $p$. 93). Knowledge, what it is, what counts as knowledge, and whose knowledge counts (Hodgson \& Canvin, 2005) will continue to vex researchers who utilize narrative inquiry. In addition, we cannot make generalizations beyond Burcu's lived experiences. However, narrative inquiry is valuable as a lens to explore and understand life experiences and the subjective nature that accompanies them. When we use narratives, "we make ourselves experimental subjects and treat our experiences as primary data" (Jackson, 1989, p. 80). Barthes (1977) explains a narrative as "international, transhistorical, transcultural: it is simply there, like life itself" (p. 79). Barhuizen and Hacker (2009) view "narrative[s] as stories of experience" (p. 2). As Ritchie \& Wilson (2000) note, "As researchers using stories in our work, we need to remind ourselves of the very nature of stories; they are not neutral objects. They invite us-even command us-into relationship with the teller" (p. 28).

Our hope is to inform the pre- and in-service teachers who may one day have ELLs in their classroom about the journeys of ELLs and how each student comes to class with a different story. As Palmer (1998) notes, "We must honor both the little stories of our lives and the big stories of the disciplines...It is a hard tension to hold-not only because academia discredits the little story but also because the little stories are the ones the students feel most comfortable with" (p. 80). Teacher candidates who accept the differences in their instructors will be primed to accept the differences in their students. $\mathrm{CN}$-incorporated instructions can be a solution to do so. The lessons we can glean from Burcu's first-hand account, and others like hers, are both foundational and a central aspect of TESOL teacher education. 


\section{References}

Atkinson, B. (2010). Teachers responding to narrative inquiry: An approach to narrative inquiry criticism. Journal of Educational Research, 103, 91-102.

Barkhuizen, G., \& Hacker, P. (2009). A collaborative narrative inquiry: Two teacher educators learning about narrative inquiry. Per Linguam: A Journal of Language Learning, 25(1), 1-16.

Bruner, J. (2003). Making stories: Law, literature, life. Cambridge, MA: Harvard University Press.

Barthes, R. (1977). Introduction to the structural analysis of narratives (S. Heath, Trans.). In R. Barthes (Ed.), Image/ music/ text (pp. 79-124). New York, NY: Hill and Wang.

Carter, C. (1993). The place of story in the study of teaching and teacher education. Educational Researcher, 22(1), 5-12.

Conle, C. (2000). Narrative inquiry: Research tool and medium for professional development, European Journal of Teacher Education, 23(1), 49-63.

Connelly, F. M., \& Clandinin D.J. (2000). Narrative understandings of teacher's knowledge. Journal of Curriculum and Supervision, 15(4), 315-331.

Curtis, A., \& Romney, M. (Eds.) (2006). Color, race, and English language teaching: Shades of meaning Mahwah, NJ: Lawrence Erlbaum Associates.

de Jong, E., \& Harper, C. (2005). Preparing mainstream teachers for English language learners: Is being a good teacher good enough? Teacher Education Quarterly, 32(2), 101-124.

Delano-Oriaran, O. O., \& Meidl, T. D. (2012). Critical conversations: Developing white teachers for diverse classrooms. Journal of Praxis in Multicultural Education, 7(1), Article 1.

Echevarria, J., Vogt, M. E., \& Short, D. (2004). Making content comprehensible for English learners: The SIOP model (2nd Ed.). Boston: Allyn \& Bacon.

Feistritzer, C. E. (2011). Profile of teachers in the U.S. 2011. Washington, DC: National Center for Education Information.

Gay, G. (2010). Culturally responsive teaching: Theory, research, and practice. New York, NY: Teachers College Press.

He, Y., \& Cooper, J. (2011). Struggles and strategies in teaching: Voices of five novice secondary teachers. Teacher Education Quarterly, 38(2), 97-116.

Hellstén, M., \& Goldstein-Kyaga, K. (2011). Negotiating professional career through intercultural pedagogy: Narrative analysis of two senior university lecturers. In S. Trahar (Ed.), Learning teaching narrative inquiry: Travelling in the borderlands (pp. 157-171). Amsterdam: John Benjamins Publishing. 
Hodgson T. P., \& Canvin K. (2005). Translating health policy into research practice. In L. Lowes and I. Hulatt (Eds.), Involving service users in health and social care research (pp. 48-65). London: Routledge.

Jackson, M. (1989). Paths toward a clearing: Radical empiricism and ethnographic inquiry. Bloomington, IN: Indiana University Press.

Jones, K. (2003). The turn to a narrative knowing of persons: One method explored. Journal of Research in Nursing, 8(1), 60-71.

Kennedy, S., \& Trofimovich, P. (2008). Intelligibility, comprehensibility, and accentedness of L2 speech: The role of listener experience and semantic context. Canadian Modern Language Review, 64(3), 459-489.

Kim, S., Ates, B., Grigsby, Y., \& Lee, G. (2013). Incorporating our own cultural narratives in TESOL education: A reflective team approach by four TESOL educators. International Journal of Education and Culture, 2 (3), 177-194.

Kim, S., Ates, B., Grigsby, Y., \& Lee, G. (2013). Incorporating our own cultural narratives in TESOL Education: A reflective team approach by four TESOL educators. In J. E. Jernigan, (Ed.), Empirical language research: Letting the data speak for themselves (pp. 1-22). Niagara Falls, NY: Untested Ideas Research Center.

Kim, S., Grigsby, Y., \& Micek, T. (2013). Addressing professional dispositions for Teaching P-12 English language learners: Why, when, and how. International Journal of TESOL and Learning, 2(2), 65-80.

Kim, S., Micek, T., \& Grigsby, Y. (2013). Investigating professionalism in ESOL teacher education through critical incident analysis and evaluation. International Journal of TESOL and Learning, 2 (3), 175-190.

Linn, D. (2010). Using cultural autobiographies in pre-service teacher education. National Teacher Education Journal, 3(2), 175-182.

Lippi-Green, R. (2012) English with an accent: Language, ideology and discrimination in the United States, (2nd ed.). New York: Routledge.

Nieto, S. (2010). Language, culture, and teaching. Critical perspectives (2nd ed.). New York, NY: Routledge.

Palmer, P. J. (1998). The courage to teach. San Francisco: Jossey-Bass.

Palmer, P.J. (2012). The heart of a teacher: Identity and integrity in teaching. Retrieved January 2, 2014, from http://www.couragerenewal.org/images/stories/pdfs/rr_heart.pdf

Ritchie, J. S., \& Wilson, D. E. (2000). Teacher narrative as critical inquiry: Rewriting the script. New York: Teachers College.

Spradlin, L. (2011). Diversity matters: Understanding diversity in schools. Independence, KY: Cengage Learning.

U.S. Census Bureau. (2010). An older and more diverse nation by midcentury. Retrieved from 
http://www.census.gov/newsroom/releases/archives/population/cbOS123.html 